\title{
Body Weight Effect on Body Image among Gym Users and Non-Gym Users
}

\author{
Sonal D. Parmar ${ }^{1 *}$, Minakshi D. Desai ${ }^{2}$
}

\section{ABSTRACT}

Body image relates to how a person thinks and feels about his or her own body. Body image plays crucial role for the Indian gym user adults for their physical look. Gym users often are concerned about their physical appearance, dissatisfied with their look and weight, or want to lose weight. The aim of the present study was to find out the difference in body image between adult gym users and non-gym users and to study the impact of weight difference in body image among adults. The sample consisted of 60 gym user adults and 60 non-gym user adults. Gym users were selected randomly from various health clubs of Rajkot city and non-gym users were selected from areas of Rajkot city in Gujarat. Body image scale constructed by Dean Jade was used to measure body image among gym user and non-gym user's adults. The data was analyzed in terms of mean, SD, and 't'test. The result of t-test revealed significant difference in body image between adult gym users and non-gym users. Gym users were more dissatisfied with their body image than non-gym users. Non-gym user males and females had satisfactory body image, whereas gym user males and females had dissatisfaction with their body. Similarly people having more weight were dissatisfied with their body image as compared to people having less weight.

Keywords: Body Image, Dissatisfaction, Gym users, Weight.

Body image is the dynamic perception of one's body-how it looks, feels, and moves. It is shaped by perception, emotions, physical sensations, and is not static, but can change in relation to mood, physical experience, and environment. Body image is influenced strongly by self-esteem and self-evaluation, more so than by external evaluation by others. It can, however, be powerfully influenced and affected by cultural messages and societal standards of appearance and attractiveness. Given the overwhelming prevalence of thin and lean female images and strong and lean male images common to all westernized societies, body image concerns have become widespread among Gym users.

\footnotetext{
${ }^{1}$ Research scholar, Department of psychology, Saurashtra University, Rajkot (Gujarat)

${ }^{2}$ Professor, Department of Psychology, Saurashtra University, Rajkot (Gujarat)

*Corresponding Author

(C) 2015 I S Parmar, M Desai; licensee IJIP. This is an Open Access Research distributed under the terms of the Creative Commons Attribution License (http://creativecommons.org/licenses/by/2.0), which permits unrestricted use, distribution, and reproduction in any Medium, provided the original work is properly cited.
} 
Body image relates to how a person thinks and feels about his or her own body. Body image also refers to the way we see our body and the way we think that others see our body. There are different aspects of body image.

1. The way we see our own body (Perceptual)

Our body image is not always reflection of what our body actually looks like. For example, many people in our society perceive their body to be larger or fatter than it really is. Perceptual body image is the difference between what you perceive your body to look like and what your body actually looks like.

2. The way we feel about our body's appearance (Affective)

We all feel a certain way about the way we look and aspects of our appearance. Affective body image refers to the amount of satisfaction or dissatisfaction we feel about our general appearance, our weight or shape and even about specific body parts.

3. The thoughts and beliefs we have about our own body (Cognitive)

The feelings that we have about our body and its appearance are often associated with certain Thoughts or beliefs. When we feel dissatisfied with some aspect of our body it is usually because we believe that it is not the right shape, size or color. For instance, the many boys in our society who are dissatisfied with their body shape think that they should be larger or thinner.

4. The things we do because we are dissatisfied with our body (Behavioral)

Often, feelings of dissatisfaction with the body can lead a person to avoid doing certain things that might evoke those concerns. For instance, many people who have body dissatisfaction avoid doing physical exercise with their peers.

Body image concerns have become widespread among our societies especially in Gym users. Gym users often concerned about their physical appearance, dissatisfied with their look and weight, or want to lose weight

The nature of body weight dissatisfaction is, however, slightly different in men and women. Women are more likely to judge them overweight when by objective standards they are not, whereas men are more likely to perceive themselves as underweight with respect to objective standards (Furnham \& Calnan, 1998). These perceptions suggest that both genders misperceive their weight in comparison with others of their gender, and they make judgments about their weight using an unhealthy standard. Gupta et al.,(2001) in a comparative study on weight-related body image concerns among 18-24 year old women in Canada and India found that among the Indian women, concerns about the weight of the upper torso (i.e., face, neck, shoulders, and chest) emerged as a distinct body image construct.

Forrest, \&Stuhdreher (2007) explored the relationship between body image and gender, weight, and depression. 2512 college students provided self-report data on body image, gender, 
Weight and depression in two separate waves over a 5 year period. Result indicated that being overweight significantly correlated with negative body image which in turn significantly correlated with depression. People who are overweight are more likely to have negative body image. All the studies that explored the relationship between body image and body weight found that increased weight was associated with lesser body satisfaction. Body weight was found to be the strongest predictor of negative body image regardless of gender or ethnicity (Xanthopoulos et al., 2011). The research suggests that overweight people are more prone to have less body satisfaction compared to people of normal weight. Individuals who are obese are particularly likely to have less body satisfaction (Goldfield et al., 2010). In recent times there is an increase in number of people attending gym regularly due to abnormal consciousness about weight.

Looking at this fact the present study was planned with following objectives:

1. To find out the difference in body image between adult gym users and non-gym uers.

2. To study the difference in body image between adults having more body weight and less body weight.

\section{METHOD}

\section{Sample:}

The sample consisted of 60 gym user adults and 60 non-gym user adults. Gym users were selected randomly from various health clubs of Rajkot city and non-gym users were selected from different areas of Rajkot city in Gujarat. Average age of gym user's was 31 year and nongym user's average age was 28 year.

\section{Tools:}

The following tools were employed in the present study:

\section{Personal Data Sheet:}

Personal data sheet was prepared to collect some personal information such as age, sex, height weight, whether going to gym or not.etc.

\section{Body Image Scale:}

Translated Gujarati version of body image scale constructed by Dean Jade (1998) was used to collect information on this matter. In this scale there are 18 statements; respondent has to select any one option from 4 options given for each statement. These options are; always, many times, some times, and never and are to be scored as 4321 respectively. In this scale minimum 18 and maximum score of 72 can be obtained. Low score indicates higher level of satisfaction about body image and high score indicates higher level of dissatisfaction with body image. The author of this scale reported satisfactory level of reliability and validity. 


\section{Procedure:}

Participants were contacted individually at their place of living and at theirplace of workout i.e. gym. Respondents were clearly informed about the purpose of the study. After establishing the rapport with the participants, he/she was asked to understand the general instructions, however the instructions for specific tests were provided separately. When the subjects were comfortable with instructions and ready for testing, questionnaires were given. She/he was asked to answer each and every item of all the administered questionnaires and was ensured that the responses given by him/her would be kept confidential.

\section{RESULT}

In order to examine the hypotheses framed with reference to objectives of the study data were analyzed using t-test. When the statistical analysis regarding the impact of use of gym on body image among adults were carried out interesting results was obtained. These result are presented in table no.1

Table 1: Means, SDs and t-values of body image with reference to use of gym

\begin{tabular}{|l|l|l|l|l|}
\hline Group & N & Mean & SD & 't' - Value \\
\hline Gym users & 60 & 42.42 & 8.67 & $9.33^{* *}$ \\
Non-gym users & 60 & 27.13 & 8.24 & \\
\hline Gym user males & 30 & 38.23 & 11.55 & $5.54^{* *}$ \\
Non-gym users males & 30 & 25.16 & 5.76 & \\
\hline Gym user females & 30 & 46.60 & 3.25 & $9.72^{* *}$ \\
Non-gym user females & 30 & 29.10 & 9.34 & \\
\hline
\end{tabular}

$* * \mathrm{p}<.01$

Table 1 Indicates that gym users had higher mean $(\mathrm{M}=42.42)$ for body image than non-gym users mean $(M=27.13)$. It saws that gym users are highly dissatisfied with their bodyimage than non-gym users; the t-value for the significance of difference between mean scores is 9.33, which is significant at 0.01 level. (The cut-off score for satisfaction/dissatisfaction is 37)

Further analysis was carried out to know if gym user and non-gym user males differ on body image. Similar analysis was also carried out for gym user and non-gym user females. In both the cases significant t-values (5.54 and 9.72) have been obtained. It portrayed that there is significant difference between gym user and non-user male in body image. Mean scores of gym user males and non-user males are 38.23 and 25.16 respectively reflecting that gym user males are more dissatisfied with their body image than non-gym user males. 
So far as female group is concerned similar results obtained. There is significant difference between gym user and non-user females in body image. Result reflected that gym user females are more dissatisfied $(\mathrm{M}=46.60)$ with their body image than non-gym user females $(\mathrm{M}=29.10)$.

Table 2: Means, SDs and t-values of body image with reference to weight

\begin{tabular}{|l|l|l|l|l|}
\hline Variables & $\mathbf{N}$ & Mean & SD & 't' - value \\
\hline More weight & 60 & 41.40 & 9.64 & $10.46^{* *}$ \\
& 60 & 28.10 & 0.69 & \\
\hline Gym users having more weight & 28 & 44.04 & 07.65 & 0.23 NS \\
Gym users having less weight & 32 & 41.00 & 19.51 & \\
\hline Non-gym users having more weight & 23 & 26.96 & 6.25 & 1.50 NS \\
Non-gym users having less weight & 37 & 27.24 & 4.48 & \\
& & & & \\
\hline
\end{tabular}

${ }^{* *} \mathrm{p}<.01, \mathrm{NS}=$ Not Significant

Table 2 Indicates that more weight mean $(M=41.40)$ for body image than less weight mean $(M=28.10)$. It saws that people having more weight are highly dissatisfied with their body image than people having less weight; the t-value for the significance of difference between mean scores is 10.46, which is significant at 0.01 levels.

Further analysis was carried out to know if gym users having more weight and less weight differ on body image. Similar analysis was carried out for non-gym users having moreweight and less weight in both the cases significant t-values (0.23 and 1.50) have been obtained. It portrayed that there are no significant differences among gym users having high weight and low weight in body image. Mean scores of gym users having more weight and less weight is 44.04 and 41.00 . respectively reflecting that gym users having more weight and less weight people are equally dissatisfied with their body image.

So far as non-gym users having more weight and less weight group is concerned similar result obtained. There is no significant different between non-gym users having more weight and less weight in body image. Result reflected that non-gym users having more weight and less weight are equally satisfied (26.96 and 27.24) with their body image

\section{DISCUSSION}

Every individual has perception, thoughts and feelings connected to one's body image.Estimating the body size and weight contributes to one's perception, evaluation of bodily attractiveness contributes to one's thoughts and how comfortable is a man or woman with one's 
body may evoke different feelings connected to body image. It is understood that men andwomen are victims of stereotyped portrayal of body image.

The present study aimed at investing whether any difference existed in body image among gym users and non-gym users about their body image. Result indicates that gym users are highly dissatisfied with their body image than non-gym users. More over the non-gym users were satisfied with their body image. Gym users often concerned about their physical appearance, dissatisfied with their look and weight, or want to lose weight. Exercise training can lead to significant improvements in body image and also improves body image by making people aware of their physical capabilities (McDonald \& Thompson, 1992). Most of the people think that gym is the place where they can improve their body image.Gym users concerned about their physical appearance. Theydissatisfied with their look. So they want to lose weight.

Result of the study also saws that people having more weight are highly dissatisfied with their body image than people having less weight. Results of a few studies are in support of current result; Larkin and Pines (1979) provided evidence for such a stereotype by asking their participants to read and evaluate written descriptions of individuals who differed only in terms of sex and weight. They rated overweight people more negatively than they rated people of average weight. Ackard and Peterson (2001) believe that overweight is related to dissatisfaction of body image and related behavior. The research suggests that overweight people are more prone to less body satisfaction compared to people of normal weight. Individuals who are obese are particularly likely to have less body satisfaction (Goldfield et al., 2010).

In India, body shape and weight is directly associated with their social life and future marriage life, especially for girls. In today's world, young people are constantly under the impression that they have to fit the current definition in order to fit in with society and be recognized. Young people are idolizing media images and trying to imitate them. This in turn is causing a negative effect on individualism. Usually it is observed that young people are more conscious to control their weight by restricting diet or doing physical exercise. Every person is Over conscious about harmful consequences of overweight and obesity. Overweight people are teased by their colleagues and they become victim of so many unwanted situation. Thinness is more accepted than obesity in India. Due to more cultural reforms, Indian people are more conscious for their body weight and body image. Therefore, we can conclude that they are more prone to visit health clubs to reduce their weight or build body image.

On the other hand, negative body image, or body image dissatisfaction, has been linked to a range of negative physical and psychological health concerns and risk-taking behaviors, including the development of eating disorders, less self-esteem, Depression, self-harm and suicide. So, we can't take it lightly. 


\section{CONCLUSION}

Thus, results portrayed that gym user males and females were highly dissatisfied with their body image than non-gym user males and females. Result also revealed that people having more weight are highly dissatisfied with their body image than people having less weight. We can conclude that body weight plays a crucial role in physical look of adults male and female. Obviously it is good to think about body weight as well as body image as both the factors have pervasive effects on many other psychological (e.g. eating disorders, less self-esteem, Depression, etc) and physiological (e.g. diseases like hypertension, diabetes mellitus, coronary heart disease, stroke etc.) consequence.

\section{REFERENCES}

Ackard DM, Peterson CB. Association between puberty and disordered eating, body image, and other, psychological variables. Int J Eat Disord 2001; 29(2): 187-194.

American Association of University Women. (1994). Shortchanging girls, shortchanging America: Executivesummary. Washington D.C.: AAUW Educational Foundation.

Ata, R., Ludden, A. B., \& Lally, M. M. (2006). The effects of gender and family, friend, and media influenceson eating behaviors and body image during adolescence. Journal of Youth and Adolescence, 36(8).1024-1037.

Benuto, L., Haboush, A., \& Jones-Forrester, S. (2007). Research report: Compensatory efforts for bodydissatisfaction: Some gender and ethnic difference. The New School Psychology Bulletin, (5)2, 19-25

Duane A. Hargreaves , Marika Tiggemann;(2004) Idealizedmedia images and adolescent body image: "comparing" boys and girls; Body image: Vol 1(4): Dec2004; 351-361

Global Media Journal(2012) - Indian Edition/ISSN 2249-5835 Sponsored by the University of Calcutta/www.caluniv.ac.in Summer Issue / June 2012 Vol. 3/No.1

Grogan, S 2008, Body Image: Understanding body dissatisfaction in men, womenand children (second edition), New York: Routledge.

Mary L. Marcum (2010). The Construction of Body Image: Identifying Communicative Influences for Women.Thesis submitted to Texas Tech University.

McCreary, D.R \& Sasse, D.K 2002, „Gender differences in high school students"dieting behaviour and their correlates 'International Journal of Men's Health,1, 195-213.

Psi Chi, The International Honor Society in Psychology (2010) (Vol. 15, No. 3/ISSN 1089-4136)

Ramachandran, V. (1996). Illusions of body image: What they reveal about human nature. The mind-braincontinuum: Sensory processes. 29-60.

Shah Hasmukh D, Shaikh Wasim A,(2012) Singh S K National Journal of Community Medicine Vol 3 Issue 2April-June 2012

Slade, P.D 1994, What is body image? Behaviour Research and Therapy, 32, 497-502.

T. Pruzinsky (eds) Body Image: A Handbook of Theory, Research, and ClinicalPractice (142254), New York; Gilford Press.

Thompson, J.K \& Van Den Berg, P 2002, „Measuring body image attitudes amongadolescents and adults"e. 